\title{
Quantification of Seed Oil Content and Fatty Acid Profile of Jatropha cucas L. from Guizhou, China
}

\author{
Hamidou SENOU ${ }^{1,2}$, Cai X. ZHENG ${ }^{1}$, Gabriel SAMAKE ${ }^{2}$, Mamadou B. TRAORE ${ }^{1}$, Fousseni FOLEGA ${ }^{3}$ \& \\ Bakary M. TRAORE ${ }^{2}$ \\ ${ }^{1}$ College of Biological Sciences and Biotechnology, Beijing Forestry University. Beijing 100083. P. R. China \\ ${ }^{2}$ Institut Polytechnique Rural de formation et de Recherche Appliquée (IPR/IFRA), Katibougou Bp: 06, Koulikoro, \\ Mali \\ ${ }^{3}$ Université de Lomé, Laboratoire de Botanique et Écologie Végétale, Faculté des Sciences, BP 1515, Lomé, Togo \\ Correspondence: Cai X.ZHENG, College of Biological Sciences and Biotechnology, Beijing Forestry University, \\ Beijing 100083. P. R. China. Tel: 86-139-1020-9315. E-mail: zhengcx@bjfu.edu.cn
}

Received: March 2, 2016 A ccepted: Marchr 21, 2016 Online Published: March 24, 2016

doi:10.5539/ijb.v8n2p92 URL:http://dx.doi.org/10.5539/ijb.v8n2p92

\begin{abstract}
The methyl esters of fatty acids composition of the oil from jatropha curcas seeds were analyzed by gas chromatography-mass spectrometer GC-MS. Fourteen components were found to be representative with $99.52 \%$ of the total content of seed oils. The main constituents were unsaturated fatty acids (71.93\%) and saturated fatty acids $(27.59 \%)$. For the saturated fatty acids composition such as palmitic and stearic acid, the rate was $15.80 \%$ and $10.79 \%$, respectively. Linoleic acid (39.58\%) and oleic acid (30.41\%) were obtained in highest concentration among the unsaturated fatty acids identified in the seeds oil of Jatropha curcas from Guizhou. This value also justifies the fluidity of the oil at room temperature. A high percentage of polyunsaturated fatty acids (39.58\%) and a slightly lower rate of monounsaturated fatty acids (32.35\%) were also observed. The seed oils profile of Guizhou Jatropha curcas presents the desirable fatty acid C14 to C18 and interesting features for the biodiesel production.
\end{abstract}

Keywords: FAMEs, GC-MS, Guizhou, Jatropha curcas, seed oils, quantification

\section{Introduction}

Jatropha is native to Central America and is widespread in South America, Southeast Asia, India, Africa and China (Adebowale \& Adedire, 2006; Qian, Shi, \& Yun, 2010; Richard \& NeBambi, 2010). On average, the seeds contain $35 \%$ of non-edible oil. Jatropha grows easily from seeds that germinate about 10 days after sowing, or from cuttings.

Indeed, the residues from the oil purification process can be used for the manufacture soap large scale in rural areas and giving women the opportunity to earn additional income and strengthen their economic position. The oil cake as another byproduct of the extraction of oil, can be used as animal feed after elimination of the toxin. Jatropha oil also allows the manufacture of the lacquer after oxidation with iron oxides and a colorant. The oil are extracted phorbol esters, active product in the fight against certain insects and mollusks harmful for agriculture (Heller, 1996). Jatropha curcas is a multipurpose plant with many attributes. The tree is mainly used as a hedge to demarcate plots of farmers and is deemed able to grow on any soil type and requires no additional water intake. The leaves are used in traditional medicine against coughs or as an antiseptic. Without special maintenance, the plant can be grown in low to high rainfall areas and can produce fruit after a year (Behera, Srivastava, Tripathi, Singh, \& Singh, 2010). One hectare can allow cultivation 1500 to 2500 feet of Jatropha and adult tree produces between 2 and $6 \mathrm{~kg}$ of seeds per year usually in two fruiting depending on the cultivar used and the rich soil. 5 kilos of fruit yield 1 liter of bio-fuel. Jatropha curcas can produce approximately 1.5 tons of oil per hectare(King et al., 2009). The oil extracted from the seeds of Jatropha Curcas is not edible or toxic, because of its phorbol ester content, but can be utilized to produce biodiesel fuel, soap production and lamp oil (Emil, Yaakob, Kumar, Jahim, \& Salimon, 2010; Liu et al., 2012; Rathbauer, Sonnleitner, Pirot, Zeller, \& Bacovsky, 2012). The seeds oil processed into biodiesel is a fuel less polluting than fossil diesel fuel (Prankl \& Schindlbauer, 1998).

In China the cultivation of Jatropha has received much attention and consideration. Various Jatropha projects have been implemented by the southwestern provincial governments of China such as Sichuan, Yunnan, and 
Guizhou. In 2006 these provinces had an area of more than 120,000 hectares distributed as following: Yunnan with 85,000 hectares, Sichuan with 28000 hectares and Guizhou with 12,000 hectares(Liu, Ye, Pu, \& Tang, 2012). The seed oils may also be used directly in diesel engines as a substitute for petroleum diesel. The process for producing biodiesel is called transesterification. It is to react an alcohol (methanol or ethanol) on vegetable oil pretreated in the presence of a catalyst (sodium hydroxide). This method modifies chemically the fatty body structure (oil) with an alcohol to form ester compounds, and reduces the viscosity of oil (Knothe, 2010; Ong, Mahlia, Masjuki, \& Norhasyima, 2011; Sahoo et al., 2009; Silitonga et al., 2011). The Biodiesel characteristics vary widely, especially depending on the oil source and the type of alcohol used for transesterification (Xue et al., 2009). The gas chromatography- mass spectrometry (GC-MS) is the mainly technique employed for the quantification of fatty acid methyl ester in samples (Costa et al., 2015; Karpagam, Raj, Ashokkumar, \& Varalakshmi, 2015).

The aim of this study was to evaluate quantitatively by gas chromatography- mass spectrometry the different fatty acid methyl esters contain in the seed oil of Jatropha curcas from Guizhou province in China.

\section{Materials and Methods}

\subsection{Plant Materials}

Jatropha curcas seeds were collected during September, 2014 from Guizhou province in China. The seeds were stored at $4^{\circ} \mathrm{C}$ before use. The grown seeds were collected and the damaged seeds were discarded.

\subsection{Oil Content Estimation and Chromatographic Separation of FAMEs}

The seed oils were extracted by Soxthlet apparatus with $180 \mathrm{ml}$ of $\mathrm{n}$-hexane as solution at $80^{\circ} \mathrm{C}$ for $6 \mathrm{~h}$. The grinded seeds used was a sample of $5 \mathrm{~g}$ and after extraction the solvent was evaporated in a rotary evaporator with a controlled water temperature at $35^{\circ} \mathrm{C}$. The extraction method was duplicated and then the means and the standard deviations were calculated.

To convert the oil to methyl ester, about two drops of sample were added within $0.5 \mathrm{ml} 2 \mathrm{~N} \mathrm{KOH}$ in methyl alcohol and in $1.5 \mathrm{ml} \mathrm{n}$-hexane. After mixing the solution by vortex for $2 \mathrm{~min}$, the supernatant of the top layer containing was extracted and used for GC injection. The fatty acid methyl esters (FAMEs) were quantified by gas chromatography coupled with mass spectrometry (GC/MS QP2010 Shimadzu, Japan). The capillary column (Restek Corporation, USA) at $30 \mathrm{~m}$ length, $0.25 \mathrm{~mm}$ internal diameter and $0.250 \mu \mathrm{m}$ thickness were used with the initial temperature at $150^{\circ} \mathrm{C}$, which was then ramped up by $8^{\circ} \mathrm{C} / \mathrm{min}$ to $190^{\circ} \mathrm{C}$ and kept at $230^{\circ} \mathrm{C}$ for $18 \mathrm{~min}$. The injector temperatures was $280^{\circ} \mathrm{C}$. The detector temperatures was $300^{\circ} \mathrm{C}$. The Pressure was retained at $100 \mathrm{KPa}$ and the solvent used cut time was $1.8 \mathrm{~min} .1 \mu \mathrm{l}$ of the prepared standard sample were injected into the GC column by using auto injection system. The Helium was used as the carrier with a flow rate of $1 \mathrm{ml} / \mathrm{min}$ and with a split mode at $1 / 30$. The NIST11.LIB and NIST11S.LIB were used to identify the fatty acid methyl ester peaks. The relative concentration of each FAME was achieved by peak area using a capillary gas chromatograph equipped with a flame ionization detector (GC-FID 17A, Shimadzu, Kyoto, Japan).

\section{Results and Discussion}

The results of oil extraction showed that the seeds of Jatropha curcas from Guizhou contain $63.80 \pm 0.5 \%$ of oils. In our studies, we found that the seed oil content of Jatopha curcas is higher. This result confirms that the solvent extraction provides a maximum amount of seed oils. Shivani, Khushbu, Faldu, Thakkar, and Shubramanian (2011) found that the solvent extraction using hexane as solution gave higher oil yields $78.66 \pm 0.9 \%$. The same higher oil content was observed in the seed of jatropha crucas from Thailand (64.23 $\pm 0.24 \%$ ), from Malyasia (63.16 \pm $0.35 \%)$ and from Indonesia $(61.36 \pm 0.10 \%)$ (Emil et al., 2010). However Verma and Verma (2015) found the highest oil yield (42\%) in jatropha curcas seed from Rajasthan in Indian. The total oil content reported by Mazumdar et al. (2013) was found to vary from 30 to $42 \%$ by Soxhlet extraction with hexane as solution.

The Fatty Acid Methyl Esters compositions for the seed oil of Jatropha curcas species from Guizhou were determined by gas chromatography-mass spectrometer. The GC-MS chromatogram is shown in Figure 1. The analyses were repeated two times and the average of concentration (\%) and the standard deviation values were reported in Table 1. The retention time among the two measurement results was also tabulated. The Table 1 shows that fourteen fatty acids composed the Jatropha curcas seed oil and representing $99.52 \%$ of the total seed oils content. The oil is very rich in oleic acids (30.41\%) and linoleic acids (39.58\%) and can be classified as unsaturated oil. 


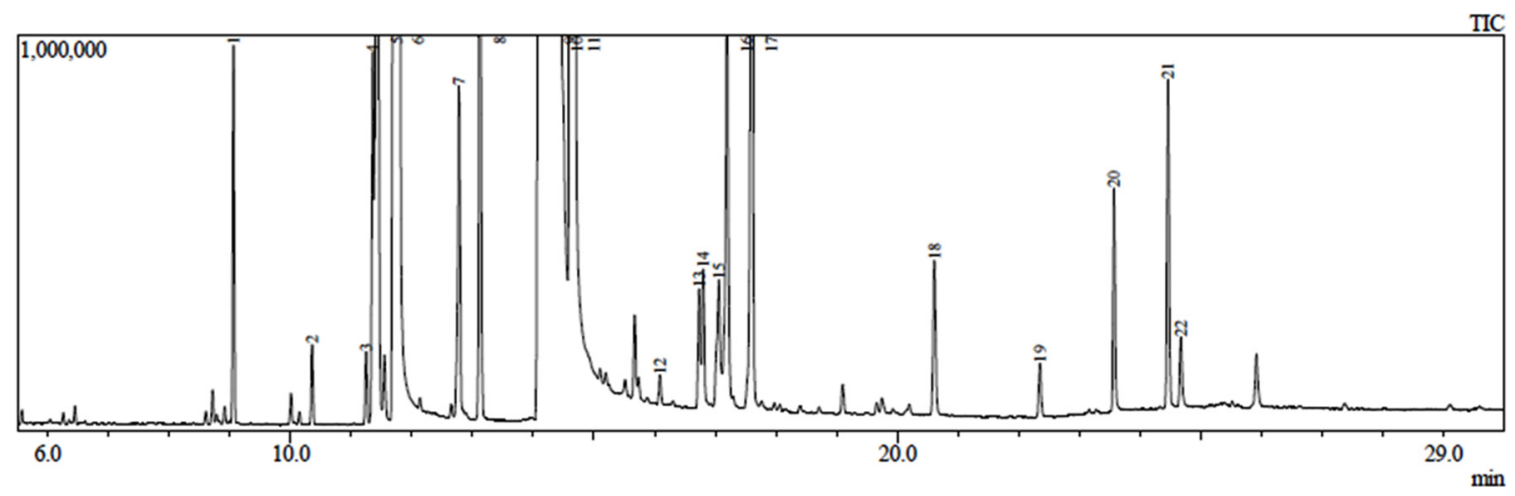

Figure 1. GC-MS chromatogram of FAMEs

1: Tetradecanoic acid; 2: Pentadecanoic acid; 3: 7, 10-Hexadecadienoic acid; 4: alpha.-Chloroethyl trimethylsilane; 5: 9-Hexadecenoic acid; 6: Hexadecanoic acid; 7: cis-10-Heptadecenoic acid; 8: Heptadecanoic acid; 9: 12-cisoctadecadienoate; 10: 9-Octadecenoic acid; 11: Octadecanoic acid;

12: Nonadecanoic acid; 13: 9-Octadecynoic acid; 14: Cyclopropaneoctanoic acid; 15: Oxiraneoctanoic acid; 16: 11-Eicosenoic acid; 17: Eicosanoic acid; 18: Docosanoic acid; 19: Tricosanoic acid; 20: Tetracosanoic acid; 21: Squalene; 22: Pentacosanoic acid.

Table 1. Fatty acids composition in seed oil

\begin{tabular}{lllll}
\hline Fatty acids & Chemical formula & Acronym & Composition \% & Retention Time \\
\hline Myristic acid & $\mathrm{C}_{14} \mathrm{H}_{28} \mathrm{O}_{2}$ & $\mathrm{C} 14: 0$ & $0.11 \pm 0.01$ & $9.05 \pm 0.01$ \\
Pentadecanoic acid & $\mathrm{C}_{15} \mathrm{H}_{30} \mathrm{O}_{2}$ & $\mathrm{C} 15: 0$ & $0.03 \pm 0.01$ & $10.35 \pm 0.01$ \\
Palmitoleic acid & $\mathrm{C}_{16} \mathrm{H}_{30} \mathrm{O}_{2}$ & $\mathrm{C} 16: 1$ & $1.62 \pm 0.22$ & $11.41 \pm 0.01$ \\
Palmitic acid & $\mathrm{C}_{16} \mathrm{H}_{30} \mathrm{O}_{2}$ & $\mathrm{C} 16: 0$ & $15.80 \pm 0.36$ & $11.76 \pm 0.03$ \\
Hexadecenoic acid & $\mathrm{C}_{17} \mathrm{H}_{32} \mathrm{O} 2$ & $\mathrm{C} 17: 1$ & $0.14 \pm 0.04$ & $12.77 \pm 0.01$ \\
Heptadecanoic acid & $\mathrm{C}_{17} \mathrm{H}_{34} \mathrm{O} 2$ & $\mathrm{C} 17: 0$ & $0.22 \pm 0.04$ & $13.12 \pm 0.01$ \\
Linoleic acid & $\mathrm{C}_{18} \mathrm{H}_{32} \mathrm{O}_{2}$ & $\mathrm{C} 18: 2$ & $39.58 \pm 4.07$ & $14.24 \pm 0.06$ \\
Oleic acid & $\mathrm{C}_{18} \mathrm{H}_{34} \mathrm{O}_{2}$ & $\mathrm{C} 18: 1$ & $30.41 \pm 4.54$ & $14.36 \pm 0.06$ \\
Stearic acid & $\mathrm{C}_{18} \mathrm{H}_{36} \mathrm{O}_{2}$ & $\mathrm{C} 18: 0$ & $10.79 \pm 0.21$ & $14.65 \pm 0.04$ \\
Eicosenoic acid & $\mathrm{C}_{20} \mathrm{H}_{38} \mathrm{O}_{2}$ & $\mathrm{C} 20: 1$ & $0.19 \pm 0.06$ & $17.19 \pm 0.01$ \\
Arachidic acid & $\mathrm{C}_{20} \mathrm{H}_{40} \mathrm{O}_{2}$ & $\mathrm{C} 20: 0$ & $0.5 \pm 0.11$ & $17.59 \pm 0.01$ \\
Behenic acid & $\mathrm{C}_{22} \mathrm{H}_{44} \mathrm{O}_{2}$ & $\mathrm{C} 22: 0$ & $0.07 \pm 0.02$ & $20.61 \pm 0.01$ \\
Lignoceric acid & $\mathrm{C}_{24} \mathrm{H}_{48} \mathrm{O}_{2}$ & $\mathrm{C} 24: 0$ & $0.07 \pm 0.03$ & $23.57 \pm 0.00$ \\
Pentacosanoic acid & $\mathrm{C}_{25} \mathrm{H}_{50} \mathrm{O}_{2}$ & $\mathrm{C} 25: 0$ & $0.02 \pm 0.01$ & $24.67 \pm 0.00$ \\
\hline
\end{tabular}

The Figure 1 shows that the main constituents were unsaturated fatty acids (71.93\%), saturated fatty acids (27.59\%) and $0.48 \%$ for the other contains. The content of total unsaturated fatty acids was determined with a high percentage of polyunsaturated fatty acids $(39.58 \%)$ and a slightly lower rate of monounsaturated fatty acids $(32.35 \%)$. Figure 2. The amount of unsaturated fatty acid (77.24\%) previously reported by (Wang, Lin, \& Xu, 2008) was slightly higher than amount observed in our study. Among the fourteen components of fatty acid methyl esters, the Palmitoleic acid, linoleic acid and oleic acid were in a higher content for unsaturated acid and composed $1.62 \pm 0.22,39.58 \pm 4.07$ and $30.41 \pm 4.54$ respectively. The Palmitic acid and stearic acid were predominant for the other saturated fatty acid and composed $15.80 \pm 0.36$ and $10.79 \pm 0.21$ respectively. whereas the other fatty acids including Pentadecanoic acid, Hexadecenoic acid, Heptadecanoic acid, Eicosenoic acid, Arachidic acid, Behenic acid and Lignoceric acid were found in very low concentrations. Kai-jin, Quan, Guan-feng, Xiang-xi, and LINAping (2008) found in Jatropha curcas seed oil from Sichuan and Guizhou province that the Fatty acid composition was dominant by the linoleic acid 41 and $44 \%$ respectively. In general the vegetable oil with higher content of monounsaturated fatty acid was found to be a promising option to fossil fuels, so, fatty acid content of Guizhou Jatropha curcas rich in oleic acid depicted a promising option to fossil fuel. 


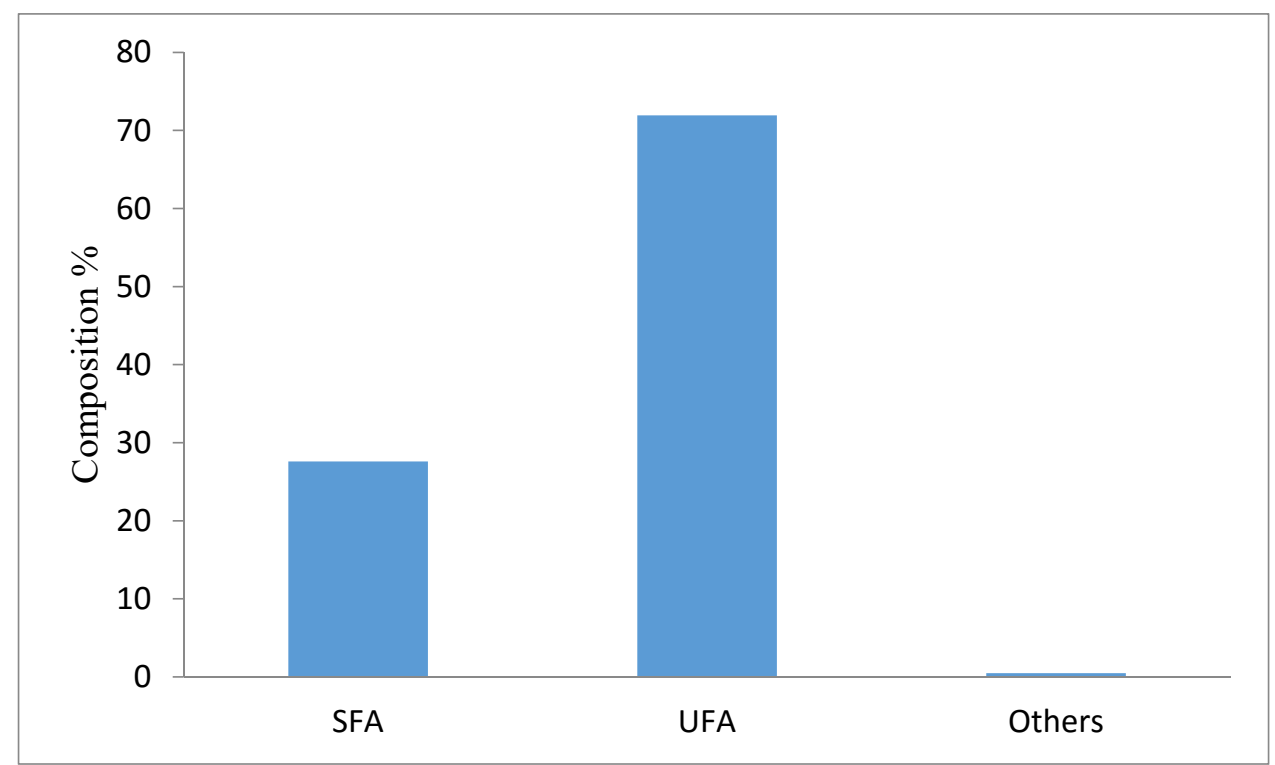

Figure 2. Constituents of fatty acid from seed oil

SFA Saturated Fatty Acid.

UFA Unsaturated Fatty Acid.

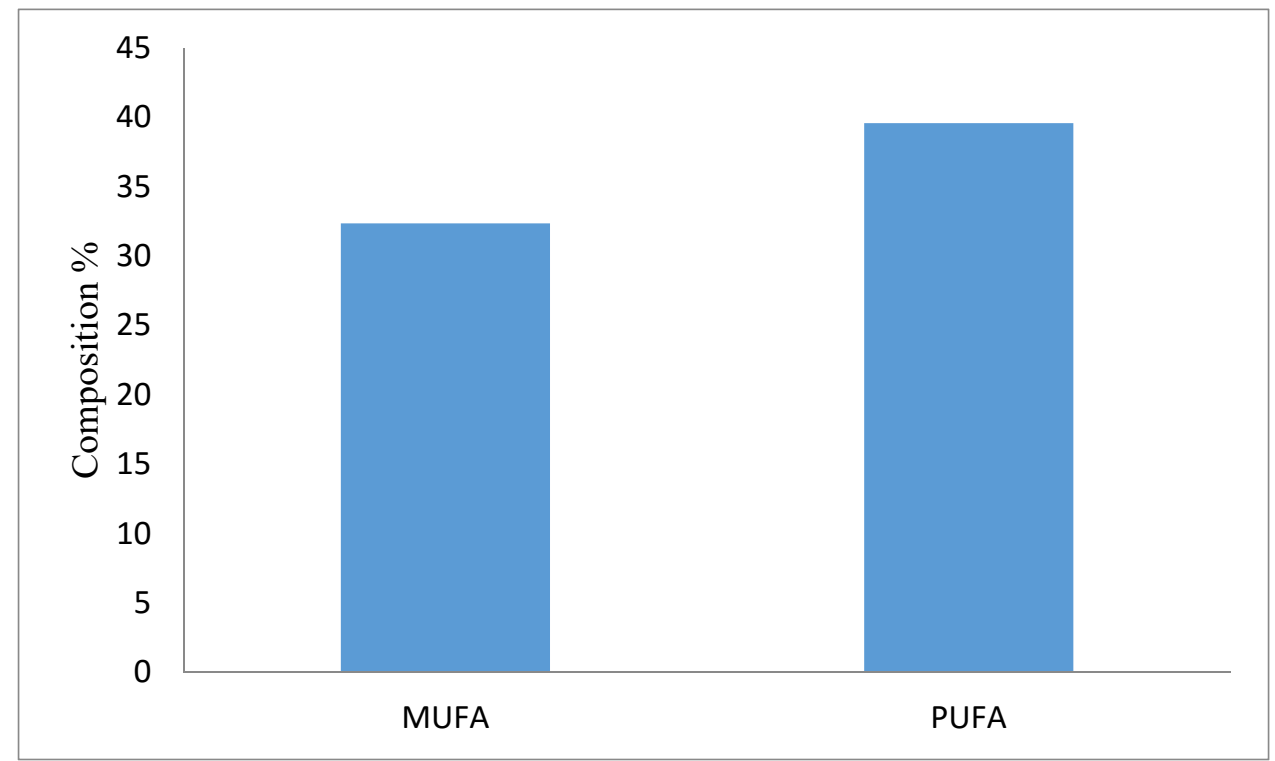

Figure 3. Constituents of unsaturated fatty acid

MUFA: Monounsaturated fatty acid.

PUFA: Polyunsaturated fatty acid.

\section{Conclusion}

The present study evaluated the oil and fatty acid methyl esters content in the seed of Jatropha curcas collected from Guizhou province in the south west of China. The seeds have a higher oil content. The major saturated fatty acid was Palmitic and Stearic acid. Palmitoleic, linoleic and oleic acid were the dominated unsaturated fatty acid. The oil is of unsaturated type and can be classified as an oleic-linoleic oil. This higher content of unsaturated fatty acids in the oils makes them fluid at room temperature. The highest amount of monounsaturated fatty acid found in the seed oil fuel may have excellent characteristics in stability and flow properties at low temperature and gave 
it an excellent feed stock for biodiesel production. In general the properties of biodiesel produced from Jatropha curcas seed oils are very similar to petroleum-based diesel and have a great potential to replace petroleum-based fuels in the long run.

\section{Acknowledgements}

The Authors would like to acknowledge the China Scholarship Council (CSC), the Ministry of Higher Education and Scientific Research of Mali and the College of Biological Sciences and Biotechnology department of Beijing Forestry University for supporting this research.

\section{References}

Adebowale, K. O., \& Adedire, C. O. (2006). Chemical composition and insecticidal properties of the underutilized Jatropha curcas seed oil. African Journal of Biotechnology, 5(10), 901-906.

Behera, S. K., Srivastava, P., Tripathi, R., Singh, J. P., \& Singh, N. (2010). Evaluation of plant performance of Jatropha curcas L. under different agro-practices for optimizing biomass - A case study. Biomass and Bioenergy, 34(1), 30-41. http://dx.doi.org/10.1016/j.biombioe.2009.09.008

da Luz Costa, J., da Silva, A. L. L., Bier, M. C. J., Brondani, G. E., Gollo, A. L., Letti, L. A. J., ... \& Soccol, C. R. (2015). Callus Growth Kinetics of Physic Nut (Jatropha curcas L.) and Content of Fatty Acids from Crude Oil Obtained In Vitro. Applied biochemistry and biotechnology, 176(3), 892-902. http://dx.doi.org/10.1007/ s12010-015-1618-y

Emil, A., Yaakob, Zahira, Kumar, M. N. Satheesh, Jahim, J. M., \& Salimon, J. (2010). Comparative Evaluation of Physicochemical Properties of Jatropha Seed Oil from Malaysia, Indonesia and Thailand. Journal of the American Oil Chemists Society, 87(6), 689-695. http://dx.doi.org/10.1007/s11746-009-1537-6

Heller, J. (1996). Physic nut. Jatropha curcas L. Promoting the conservation and use of underutilized and neglected crops. 1. Paper presented at the Institute of Plant Genetics and Crop Plant Research, Gatersleben/ International Plant Genetic Resources Institute.

Kai-jin, W., Quan, W., Guan-feng, L., Xiang-xi, X. I. A. O., \& A-ping, L. (2008). Physicochemical properties and fatty acid composition of Jatropha curcas seed oil in different areas. Journal of Fujian College of Forestry, 28(4), 361-364.

Karpagam, R., Raj, K. J., Ashokkumar, B., \& Varalakshmi, P. (2015). Characterization and fatty acid profiling in two fresh water microalgae for biodiesel production: lipid enhancement methods and media optimization using response surface methodology. Bioresource technology, 188, 177-184. http://dx.doi.org/10.1016/j. biortech.2015.01.053

King, A. J., He, W., Cuevas, J. A., Freudenberger, M., Ramiaramanana, D., \& Graham, I. A. (2009). Potential of Jatropha curcas as a source of renewable oil and animal feed. J Exp Bot, 60(10), 2897-2905. http://dx.doi.org/10.1093/jxb/erp025

Knothe, G.. (2010). Biodiesel and renewable diesel: A comparison. Progress in Energy and Combustion Science, 36(3), 364-373. http://dx.doi.org/10.1016/j.pecs.2009.11.004

Liu, X., Ye, M., Pu, B., \& Tang, Z. (2012). Risk management for Jatropha curcas based biodiesel industry of Panzhihua Prefecture in Southwest China. Renewable and Sustainable Energy Reviews, 16(3), 1721-1734. http://dx.doi.org/10.1016/j.rser.2011.12.001

Liu, Y. Y., Lu, H. F., Jiang, W., Li, D. S., Liu, S. J., \& Liang, B. (2012). Biodiesel Production from Crude Jatropha curcas L. Oil with Trace Acid Catalyst. Chinese Journal of Chemical Engineering, 20(4), 740-746. http://dx.doi.org/10.1016/S1004-9541(11)60243-7

Mazumdar, P., Dasari, S. R., Borugadda, V. B., Srivasatava, G., Sahoo, L., \& Goud, V. V. (2013). Biodiesel production from high free fatty acids content Jatropha curcas L. oil using dual step process. Biomass Conversion and Biorefinery, 3(4), 361-369. http://dx.doi.org/10.1007/s13399-013-0077-3

Ong, H. C., Mahlia, T. M. I., Masjuki, H. H., \& Norhasyima, R. S. (2011). Comparison of palm oil, Jatropha curcas and Calophyllum inophyllum for biodiesel: A review. Renewable and Sustainable Energy Reviews, 15(8), 3501-3515. http://dx.doi.org/10.1016/j.rser.2011.05.005

Prankl, H., \& Schindlbauer, H. (1998). Oxidation stability of fatty acid methyl esters. In 10th European conference on biomass for energy and industry (pp. 8-11). 
Qian, J. F., Shi, H. X., \& Yun, Z. (2010). Preparation of biodiesel from Jatropha curcas L. oil produced by twophase solvent extraction. Bioresource Technology, 101(18), 7025-7031. http://dx.doi.org/10.1016/j.biortech. 2010.04.018

Rathbauer, J., Sonnleitner, A., Pirot, R., Zeller, R., \& Bacovsky, D. (2012). Characterisation of Jatropha curcas seeds and oil from Mali. Biomass and Bioenergy, 47, 201-210. http://dx.doi.org/10.1016/j.biombioe.2012. 09.040

Richard, B., \& NeBambi, L. (2010). Jatropha: a small-holder bioenergy crop; The potential for pro-poor development. Integrated Crop Management (Vol. 8): IFAD / FAO.

Sahoo, P. K., Das, L. M., Babu, M. K. G., Arora, P., Singh, V. P., Kumar, N. R., \& Varyani, T. S. (2009). Comparative evaluation of performance and emission characteristics of jatropha, karanja and polanga based biodiesel as fuel in a tractor engine. Fuel, 88(9), 1698-1707. http://dx.doi.org/10.1016/j.fuel.2009.02.015

Shivani, P., Khushbu, P., Faldu, N., Thakkar, V., \& Shubramanian, R. B. (2013). Extraction and analysis of Jatropha curcas L. seed oil. African Journal of Biotechnology, 10(79), 18210-18213. http://dx.doi.org/10.5 897/AJB11.776

Silitonga, A. S., Atabani, A. E., Mahlia, T. M. I., Masjuki, H. H., Badruddin, I. A., \& Mekhilef, S. (2011). A review on prospect of Jatropha curcas for biodiesel in Indonesia. Renewable and Sustainable Energy Reviews, 15(8), 3733-3756. http://dx.doi.org/10.1016/j.rser.2011.07.011

Verma, K. C., \& Verma, S. K. (2015). Biophysicochemical Evaluation of Wild Hilly Biotypes of Jatropha curcas for Biodiesel Production and Micropropagation Study of Elite Plant Parts. Applied Biochemistry and Biotechnology, 175(1), 549-559. http://dx.doi.org/10.1007/s12010-014-1274-7

Wang, Z. Y., Lin, J. M., \& Xu, Z. F. (2008). [Oil contents and fatty acid composition in Jatropha curcas seeds collected from different regions]. Nan Fang Yi Ке Da Хие Хие Bao, 28(6), 1045-1046.

Xue, W., Zhou, Y. C., Song, B. A., Shi, X., Wang, J., Yin, S. T., ... \& Yang, S. (2009). Synthesis of biodiesel from Jatropha curcas L. seed oil using artificial zeolites loaded with $\mathrm{CH} 3 \mathrm{COOK}$ as a heterogeneous catalyst. Natural Science, 1(01), 55-62. http://dx.doi.org/10.4236/ns.2009.11010

\section{Copyrights}

Copyright for this article is retained by the author(s), with first publication rights granted to the journal.

This is an open-access article distributed under the terms and conditions of the Creative Commons Attribution license (http://creativecommons.org/licenses/by/3.0/). 